Stereotactic

and Functional

Neurosurgery
Stereotact Funct Neurosurg 2012;90:192-200

DOI: $\underline{10.1159 / 000338251}$
Received: September 12, 2011

Accepted after revision: February 28, 2012

Published online: June 5, 2012

\title{
Laser Interstitial Thermal Therapy for Focal Cerebral Radiation Necrosis: A Case Report and Literature Review
}

\author{
Gazanfar Rahmathulla ${ }^{a}$ Pablo F. Recinos ${ }^{a, c}$ Jose E. Valerio ${ }^{b}$ Sam Chao ${ }^{a, d}$ \\ Gene H. Barnett ${ }^{\mathrm{a}}$ \\ aThe Rose Ella Burkhardt Brain Tumor and Neuro-Oncology Center, Department of Neurosurgery, Neurological \\ and Taussig Cancer Institutes, Cleveland Clinic, Cleveland, Ohio, b Department of Neurosurgery, Cleveland Clinic, \\ Weston, Fla., 'Department of Neurosurgery, Johns Hopkins Hospital, Baltimore, Md., and d Department of Radiation \\ Oncology, Neurological and Taussig Cancer Institutes, Cleveland, Ohio, USA
}

\section{Key Words}

Radiation necrosis • Laser-interstitial thermal therapy •

Brain metastases - Minimally invasive $\cdot$ Magnetic resonance thermal imaging

\begin{abstract}
Whole-brain radiotherapy and stereotactic radiosurgery (SRS) play a central role in the treatment of metastatic brain tumors. Radiation necrosis occurs in $5 \%$ of patients and can be very difficult to treat. The available treatment options for radiation necrosis include prolonged high-dose corticosteroids, hyperbaric oxygen, anticoagulation, bevacizumab, and surgical resection. We present the first report and results using laser-interstitial thermal therapy (LITT) for medically refractory radionecrosis. A 74-year-old diabetic patient who had a history of non-small cell lung cancer with brain metastases and subsequent treatment with SRS, presented with a focal lesion in the left centrum semiovale with progressively worsening edema. Image findings were consistent with radiation necrosis that was refractory despite prolonged, highdose steroid therapy. His associated comorbidities obviated alternative interventions and the lesion was not in a location amenable to surgical resection. We used laser thermal abla-
\end{abstract}

tion to treat the biopsy-proven radionecrosis. The procedure was tolerated well and the patient was discharged 48 hours postoperatively. Imaging at 7-week follow-up showed near complete resolution of the edema and associated mass effect. Additionally, the patient was completely weaned off steroids. To our knowledge this is the first report using LITT for the treatment of focal radiation necrosis. LITT may be an effective treatment modality for patients with medically refractory radiation necrosis with lesions not amenable to surgical decompression.

Copyright $\odot 2012$ S. Karger AG, Basel

\section{Introduction}

Whole-brain radiation therapy, stereotactic radiotherapy, and stereotactic radiosurgery (SRS) are commonly used as part of multimodal treatment regimens to treat brain metastases [1]. Radiation necrosis (RN) is the most common late side effect of radiation therapy, occurring in about $5 \%$ of treated patients. Cerebral RN usually develops between several months to as late as three years following treatment. It manifests clinically with focal neurological deficits or signs and symptoms of raised intracranial pressure [2].

\section{KARGER}

Fax +41613061234

E-Mail karger@karger.ch

www.karger.com
(C) 2012 S. Karger AG, Basel

$1011-6125 / 12 / 0903-0192 \$ 38.00 / 0$

Accessible online at:

www.karger.com/sfn
Gene H. Barnett, MD

Department of Neurological Surgery - S73, The Cleveland Clinic Foundation 9500 Euclid Avenue

Cleveland, OH 44195 (USA)

Tel. +1 216444 8564, E-Mail barnetg@ccf.org 
Fig. 1. 74-year-old gentleman with nonsmall cell lung cancer and newly diagnosed brain metastasis in the left centrum semiovale treated with SRS (20 Gy). PreSRS axial, sagittal, and coronal contrastenhanced $\mathrm{T}_{1}$ images showing a small contrast-enhancing lesion without perilesional edema identified during follow-up for treatment of the primary cancer.
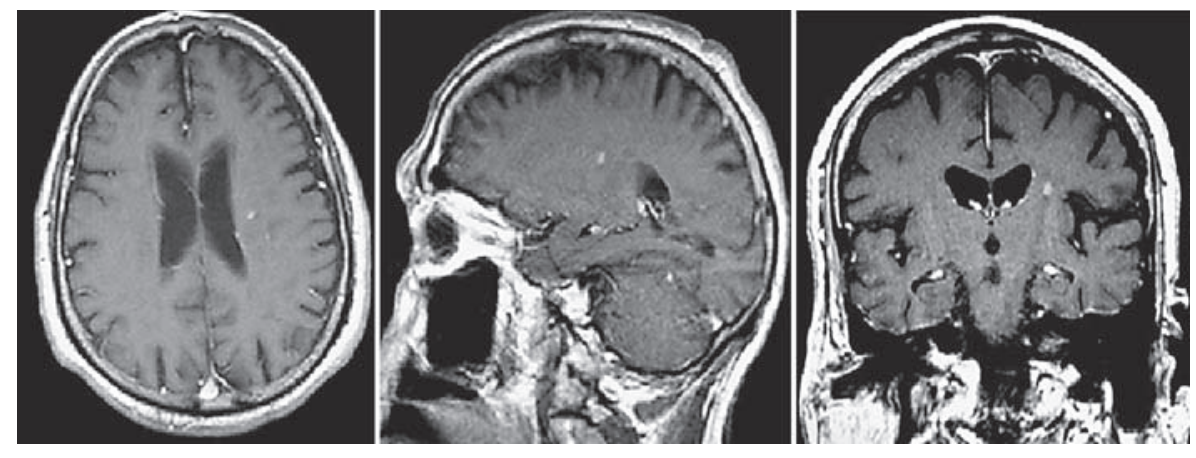

The treatment of RN can include use of corticosteroids, surgical decompression of the lesion and its associated mass effect [3], and less commonly, therapeutic anticoagulation [4] and hyperbaric oxygen [5]. Bevacizum$\mathrm{ab}(\mathrm{BEV})$ is an anti-VEGF monoclonal antibody, which has shown promise in the treatment of radionecrosis [4] but has high costs, adverse effects, and long treatment durations. Patients with medically refractory $\mathrm{RN}$ who are not candidates to receive BEV or undergo surgery have been challenging to treat as their treatment options have been limited.

Various minimally invasive techniques are being used for treating 'inoperable' or difficult to access primary and secondary brain tumors. These include cryoablation [6], high-frequency ultrasound [7], radiofrequency ablation [8], and laser thermal ablation [9]. Laser-interstitial thermal therapy (LITT) delivers focal laser energy selectively to coagulate tissue with interstitial hyperthermia and exhibits a sharp ablation boundary zone (based on the Arrhenius equation) [10]. The boundary zone can be quantitatively and noninvasively detected using magnetic resonance (MR) thermometry [11]. LITT was first used for tumor treatment by Bown in 1983 [12] and for treatment of brain tumors by Sugiyama in 1990 [13]. Subsequently, Ascher et al. [14], Roux et al. [9], and Kahn et al. [15] reported the use of LITT to treat surgically inaccessible metastases and glioblastomas. More recently Carpentier et al. $[16,17]$ have used LITT to treat cases of resistant brain metastases based on clinical and radiological criteria, with good outcomes on long-term follow-up.

In this report, we used LITT to treat a patient with medically refractory $\mathrm{RN}$ in a region not amenable to surgical decompression. To our knowledge, this is the first report illustrating the use of LITT to successfully treat medically refractory, focal cerebral RN.

Laser-Interstitial Thermal Therapy for Radiation Necrosis

\section{Methods}

A 74-year-old right-handed, diabetic man with hypertension, renal dysfunction, and coronary artery disease requiring antiplatelet medication was diagnosed with non-small cell lung cancer with brain metastases. He was treated with radiation and chemotherapy for his lung cancer and SRS for the brain metastases in the left parietal and right frontal region, with each lesion receiving $20 \mathrm{~Gy}$. One year later, a new intracranial lesion in the left centrum semiovale (adjacent to the previously treated left parietal lesion) measuring $4 \mathrm{~mm}$ in maximum diameter was treated with 20 Gy SRS (fig. 1). The SRS procedure was LINAC based using a multileaf collimator ( $\mathrm{mLC}$ ) with no other details of the procedure being available. Ten months following SRS, he presented with drooling, dysphasia, and slurred speech. Evaluation with magnetic resonance imaging (MRI) revealed that the centrum lesion had increased to $20 \mathrm{~mm}$ in maximum diameter. Additionally, there was significant perilesional edema and associated mass effect (fig. 2). A positron emission tomography-computed tomography (PET-CT) scan showed that the lesion was hypometabolic, and diffusion-weighted imaging (DWI) revealed restricted diffusion within the lesion, which was suggestive of radionecrosis.

With the clinical and radiological evidence in favor of radionecrosis, he was started on steroids to provide symptomatic relief and control the edema. He was treated for a period of 6 months with steroids; however, his symptoms did not resolve and his diabetes became poorly controlled. Medical treatment with BEV was avoided because of his associated systemic risk factors, namely use of antiplatelet medication, renal dysfunction, hypertension, and coronary artery disease. Other therapies were not deemed appropriate in this case due to lack of strong evidence supporting their use and the patient's continued clinical deterioration. The associated medical comorbidities, surgical inaccessibility, and failure of steroid therapy made us opt for LITT as an option to treat the lesion.

\section{Procedure Planning and Technique}

For the procedure we used the AutoLITT ${ }^{\circledR}$ (Monteris Medical Inc., Winnipeg, Canada) system which has received FDA 510(k) clearance for clinical use in the United States since 2009 without specific limitation for intracranial use. The device consists of: (a) a fiber-optic laser probe, (b) patient-probe interface, (c) probe driver, and (d) MR trajectory planning and thermometry workstation. This integrates with non-Monteris devices including a head-fixation device, 1.5 Tesla $(\mathrm{T})$ intraoperative MRI scanner, 

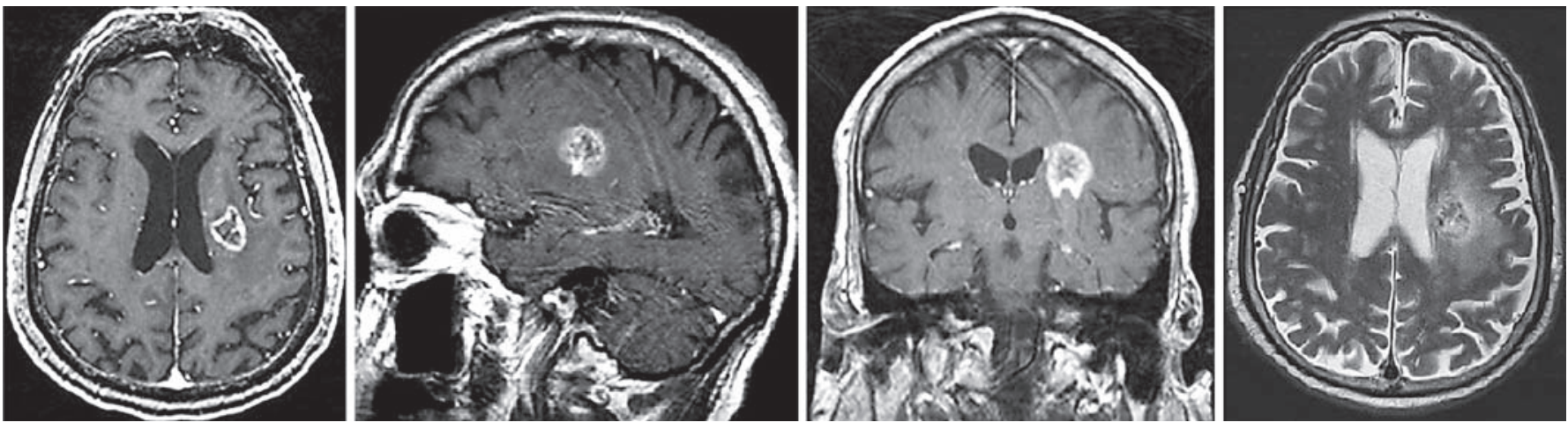

Fig. 2. The patient worsened 10 months following SRS treatment of the centrum semiovale lesion. MRI revealed an increase in size of the lesion now measuring $2.0 \times 1.5 \times 1.8 \mathrm{~cm}$ with rim enhancement and associated perilesional edema on $\mathrm{T}_{2}$ axial images (far right) despite chronic steroid use.

and a Dornier diode laser (1,064 nm), $\mathrm{CO}_{2}$-cooled, focused, pulsesequence diode laser which emits a beam $90^{\circ}$ orthogonal to the probe. The novel technologies in this device allow the laser probe to focus energy in one specific direction (perpendicular to its tip) rather than in the omnidirectional pattern of previously used bare fiber-optic laser probes. In addition, gaseous cooling is used to prevent heat dissipation to adjacent, nontargeted areas. The combination of focused energy delivery and gaseous cooling of the tip allows for conformal treatments. The probe, laser, and cooling are remotely controlled using real-time MR imaging and thermometry software.

Based on the temperatures reached within the lesion, three zones have been defined which can be visualized on the Monteris workstation while performing the procedure. Zone 1 is the region where maximal thermal damage has occurred, zone 2 is the outer limit of effective ablation, and zone 3 is where thermal changes occur without ablative effect (fig. 3). The goal of the procedure is to encompass the entire lesion within ablation zone 2 in order to be effective.

Under general anesthesia in the high-field (1.5 T) Intraoperative MR Suite (IMRISTM, Winnipeg, Canada), the patient was appropriately positioned. Trajectory planning was done using BrainLab iPlan ${ }^{\circledR}$ software (BrainLab ${ }^{\mathrm{TM}}$, Munich, Germany). The Stereotactic Miniframe (AXiiiS ${ }^{\mathrm{TM}}$, Winnipeg, Canada) was percutaneously fixed using image guidance (BrainLab ${ }^{\mathrm{TM}}$ VectorVision ${ }^{\circledR}$ Sky, Munich, Germany) locking the device to the tumorintercept trajectory as planned by the surgeon. Using a drill guide, a $5-\mathrm{mm}$ burr hole was then created along the trajectory. An MRI was done to confirm the intraoperative trajectory using the mobile MR scanner (fig. 4a). A stereotactic biopsy was performed prior to beginning the actual treatment. The biopsy revealed the presence of necrotic tissue without any evidence of tumor cells, consistent with radionecrosis. A 3-D model was used to confirm the trajectory and probe alignment, and calculate the appropriate length of the laser probe required to reach the target point (fig. 4b). Once the laser probe was in place, the ablation procedure began with the patient being in the isocenter of the MRI. Thermal ablation was started in the deepest portion of the lesion and gradually moved to the apex. The probe was manipulated axially and rotationally to focus the laser on different areas until the entire lesion was within zone 2. Once completed, the laser probe and stereotactic miniframe were removed, the burr hole and skin incision were closed in the usual fashion.

\section{Results}

Once the appropriate thermal ablation zone was accomplished, an immediate series of MR sequences were obtained consisting of $\mathrm{T}_{1}$-weighted $+/-$ contrast, $\mathrm{T}_{2}$ weighted, FLAIR, and diffusion sequences. Additional MRIs were obtained 24 hours after the procedure and at 7 weeks postoperatively.

The 24-hour postoperative MRI $\mathrm{T}_{1}$-weighted imaging revealed a central hyperintensity in the treatment location with faint peripheral contrast enhancement and $\mathrm{T}_{2} /$ FLAIR prolongation within the lesion. The cross-sectional areas were used for objective calculations and obtained by the product of the largest perpendicular measurements in two places. Comparison of the preoperative and 24-hour postoperative scans showed no significant difference in the amount of surrounding edema. The 7-week $\mathrm{T}_{1}$ images revealed marginal increase in the diameter of the lesion, a minimal rim of enhancement, and markedly decreased edema on the $\mathrm{T}_{2}$ and FLAIR sequences (fig. 5).

Clinically the patient had word-finding difficulty and conduction dysphasia in the immediate postoperative period. These symptoms gradually improved and he was discharged 2 days following the procedure. His steroids were rapidly tapered off over 14 days, and he was closely followed for symptomatic worsening. On follow-up 7 weeks after the procedure, he remained neurologically stable, with near total resolution of symptoms and off of steroids. 


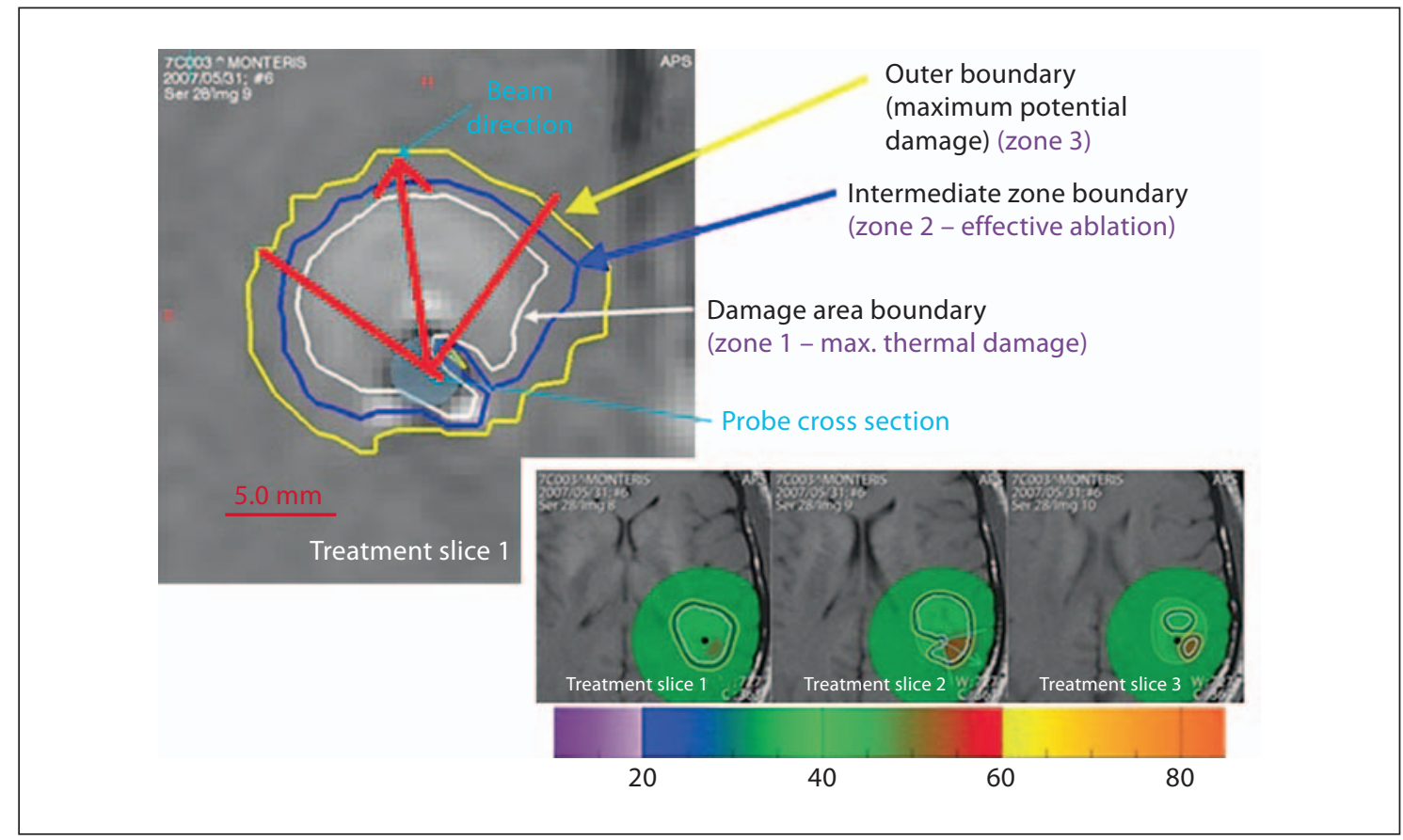

Fig. 3. Zones of thermal lesioning: zone 1 (damage area boundary) within the white line being the region of maximal thermal damage, zone 2 (intermediate zone boundary) within the blue line indicating an effective ablation, and zone 3 (outer boundary) within the yellow line indicating temperature changes without any ablative effect. This figure is only representative of the various zones of thermal ablation.
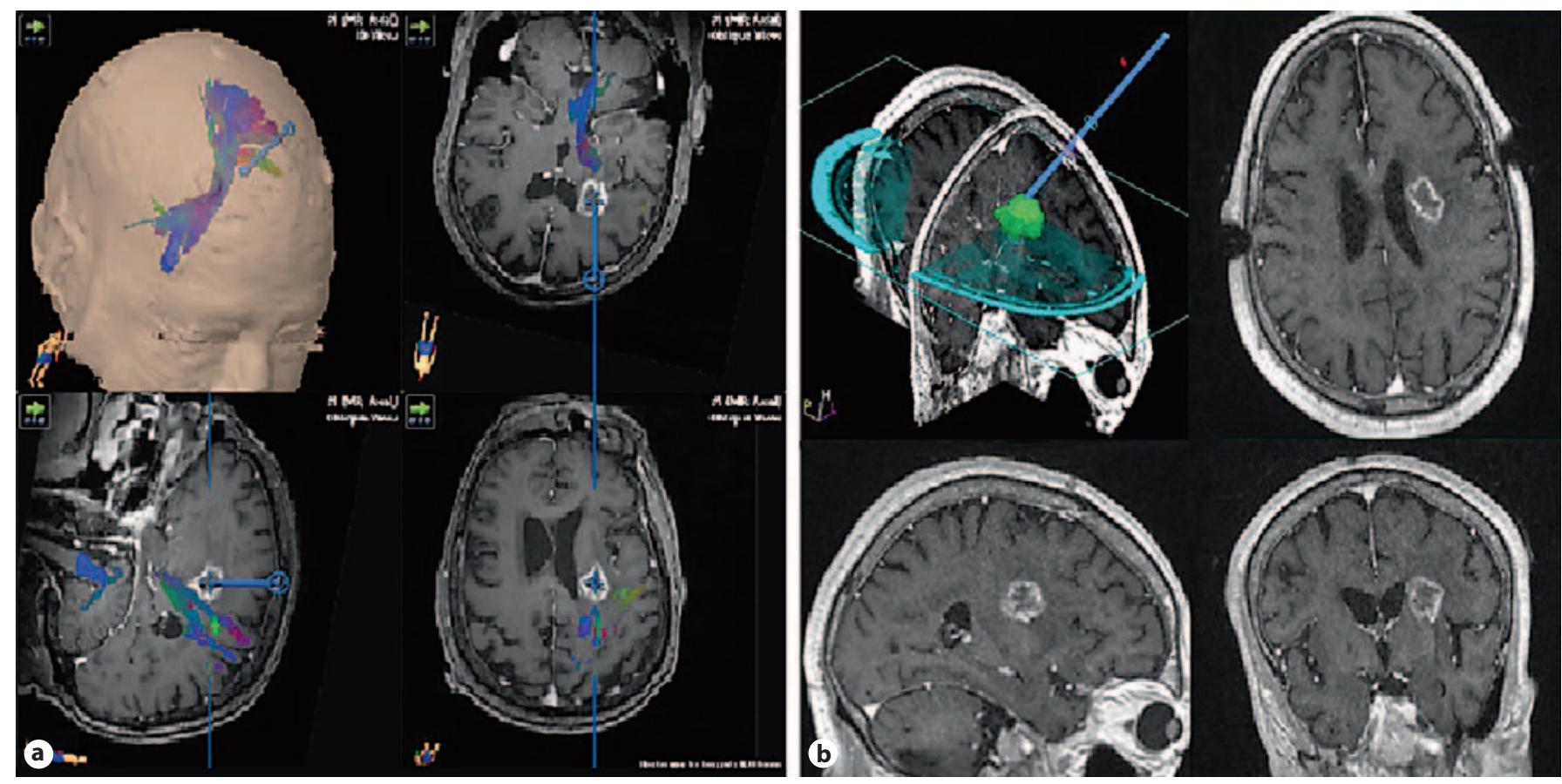

Fig. 4. a Biopsy and probe trajectory are planned prior to the start of the procedure using BrainLab iPlan ${ }^{\circledR} \operatorname{soft}^{-}$ ware. $\mathbf{b} 3 \mathrm{D}$ model and $\mathrm{T}_{1}$ contrast-enhanced images in axial, sagittal and coronal planes, with the lesion depicted as the green volume and the AutoLITT laser probe trajectory projected by the blue line. 

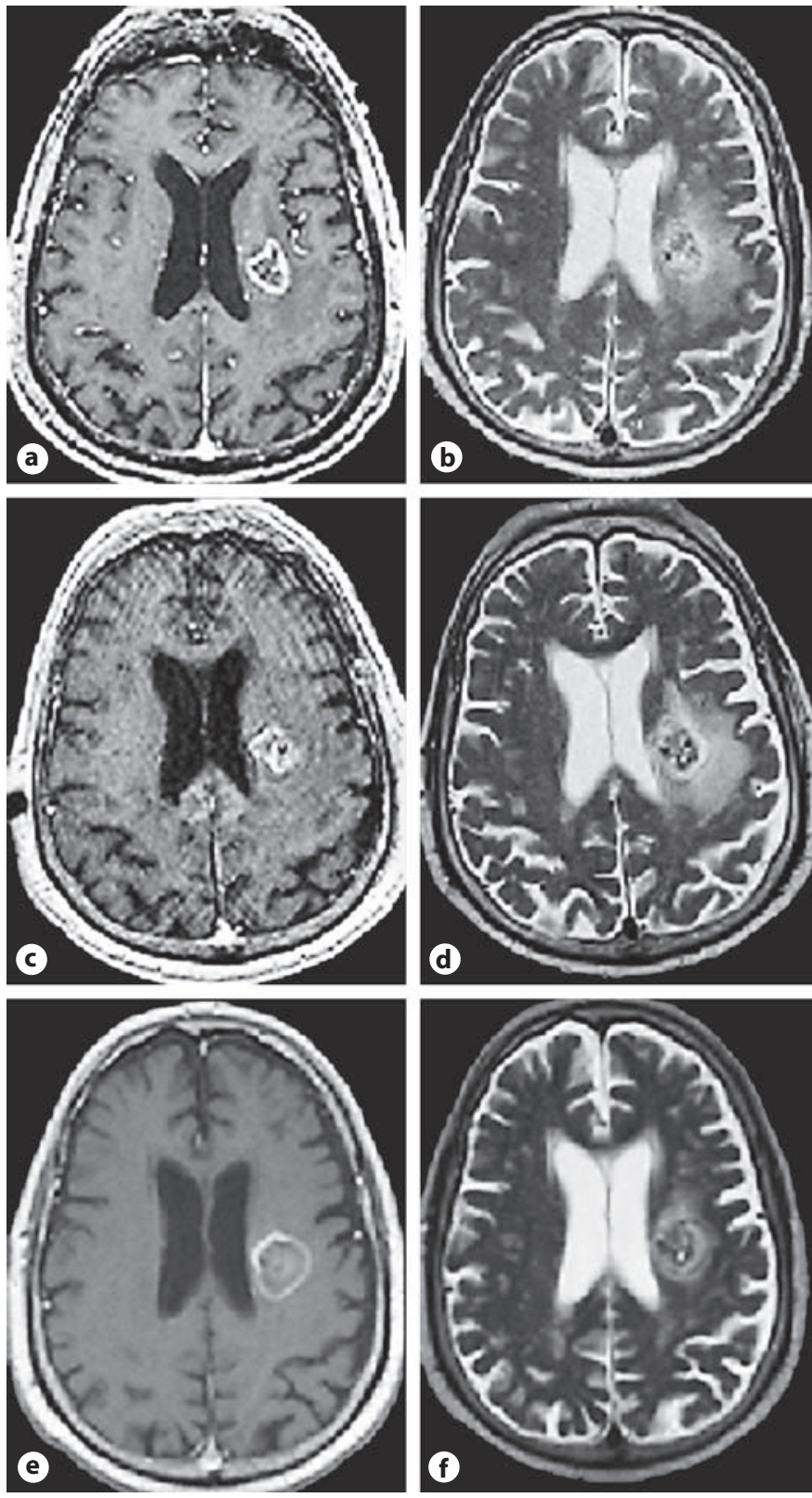

Fig. 5. a, b Pretreatment $\mathrm{T}_{1^{-}}$and $\mathrm{T}_{2}$-weighted axial images. c, $\mathbf{d}$ Immediate posttreatment 24 -hour $\mathrm{T}_{1}$ images reveal a decrease in the contrast enhancing rim with heterogeneous changes within the lesion and $\mathrm{T}_{2} \mathrm{MR}$ images show a marginal increase in the degree of edema. e, $\mathbf{f}$ Follow-up imaging at 7 weeks, axial contrast $\mathrm{T}_{1}$ images revealing an increase in lesion size with a hypointense center and thin rim of enhancement, whereas the $\mathrm{T}_{2}$ images reveal a near total resolution of the perilesional edema.

\section{Discussion}

The most significant late toxicity reported following SRS is cerebral RN, causing neurological complications in 2 to $32 \%$ of patients $[18,19]$. The characteristic findings associated with RN on imaging include: (a) an initial stabilization or decrease in lesion size 3-6 months post SRS, (b) a subsequent increase in contrast enhancement in the treated area on $\mathrm{T}_{1}$ images with significant perilesional edema, and (c) lack of flow through the lesion on perfusion MR sequences [20]. The variables associated with development of $\mathrm{RN}$ include radiation dose, volume of the tumor treated, and tumor location [21]. Typically RN develops between 1 and 3 years following treatment.

Blood-brain barrier (BBB) dysfunction and radiationinduced damage to the microglia and astrocytes play a central role in the pathophysiology of RN and edema development [22]. BBB dysfunction occurs secondary to delayed parenchymal loss, incomplete restoration of vascular endothelial cells lining the BBB [23], and vascular endothelial cell apoptosis [24]. This is followed by release of cytokines, upregulation of VEGF, and overexpression of intracellular adhesion molecule-1. Specifically, VEGF has two biological properties that contribute to the disruption of the $\mathrm{BBB}$ and propagation of $\mathrm{RN}$ : it induces angiogenesis and it increases vascular permeability $[25,26]$. Vasogenic edema ensues once the BBB is disrupted and causes further hypoxia. Cellular necrosis ensues as a result of hypoxia and results in release of HIF-1 $\alpha$ [27] secondary to the upregulation of VEGF. Histopathologically proliferating endothelial cells show weak immunoreactivity for VEGF, compared to the perinecrotic zone of astrocytes, which has high staining for VEGF. Endothelial cell proliferation appears to be strongly stimulated by VEGF produced in the perinecrotic zones, this phenomenon is easily observed in the analysis of brain specimens of patients with $\mathrm{RN}$ who were treated for head and neck cancers, where there are no intracranial tumor cells which could confound the results [28]. Telangiectasias and capillary collapse with hyalinization of vessels and fibrinoid necrosis-associated changes are seen in $\mathrm{RN}$ as well $[29,30]$. Radiation-induced damage to microglia and astrocytes in the perinecrotic zone produces large amounts of VEGF and a delayed peak in the release of TNF- $\alpha$ [31], which leads to a cycle of further cell death, perpetuates the release of inflammatory factors, and increases BBB disruption.

Medical treatment of cerebral RN has focused on controlling the vasogenic edema that results from BBB disruption. Steroids are the first-line therapy and can bring 
about significant symptomatic improvement as well as timely control of cerebral edema [2]. However, therapy can be prolonged and increasing doses may be required to bring about a therapeutic effect. Increasing steroid doses are also associated with numerous medical complications, such as hyperglycemia and increased risk of infection. BEV, a monoclonal antibody directed against VEGF, has recently been evaluated to treat RN [4]. Notable improvements have been observed in the clinical status and imaging in patients treated with BEV, adding another medical option in the treatment of these lesions $[4,32]$. However, BEV is not appropriate for all patients given its side-effect profile.

Several alternative therapies have been proposed to treat RN. Rizzoli and Pagnanelli [33] reported a dramatic improvement of 2 patients with RN while on anticoagulant (warfarin) therapy. Subsequently, Glantz et al. [34] reported their results treating 8 patients with $\mathrm{RN}$, using heparin and warfarin. More recently Happold et al. [35] reported the use of anticoagulation for 7 patients with heterogeneous lesions. Three out of 7 patients had cranial radionecrosis lesions and had modest improvement. Although Rizzoli and Pagnanelli [33] and Glantz et al. [34] reported good outcomes, their cohort of patients was small and follow-up time short, with no clear details of associated steroid use at the time of treatment. Pentoxifylline (PTX) was also been evaluated to treat RN. PTX is a methylxanthine derivative that increases blood cell deformity and decreases viscosity, thus enhancing circulation. Dion et al. [36] reported the preliminary results of PTX contributing to wound healing following radiation injury. A combination of vitamin E or tocopherol along with PTX was shown to reduce radiation-induced fibrosis of the skin [37], as well as early and late radiation adverse effects in patients treated for lung and breast cancer [38-40]. Vitamin $\mathrm{E}$ acts as a scavenger for free radicals released and protects cell membranes and may potentiate the benefits of PTX in the treatment of RN. Williamson et al. [41] studied the effects of the combination of vitamin $\mathrm{E}$ and PTX in their cohort of 11 patients with RN and concluded that the therapy may have beneficial effects. The study was limited by the concomitant use of steroids, and the heterogeneous population of patients. Along with PTX, aspirin and ticlopidine have been used, on the premise that vascular occlusive changes associated with radionecrosis may improve with antiplatelet medication. Most reports, however, are anecdotal, and since many of these patients have also received steroids concurrently, it is difficult to conclude whether the steroids, PTX, or natural history invariably led to resolution of symptoms $[41,42]$.

Laser-Interstitial Thermal Therapy for Radiation Necrosis
Hyperbaric oxygen (HBO) has been reported to have a beneficial effect in treating delayed radiation injury of tissues such as the rectum, head and neck, and mandible [43]. Hypoxia is a potent inducer of HIF-1 $\alpha$ which in turn releases other cytokines and intracellular adhesion molecule-1, which potentiate BBB breakdown [44]. By increasing tissue oxygenation, $\mathrm{HBO}$ may inhibit HIF- $1 \alpha$ induction and release, preventing the subsequent cascade and release of factors responsible for propagating the cycle of RN. Clinically, Hart and Mainous [45] first used HBO more than 30 years ago to treat 69 patients with various forms of radiation-induced injury. Various others have since reported their experience with the use of $\mathrm{HBO}$ in $\mathrm{RN}[5,46-48]$. Because of the retrospective nature of data collection, and a majority of patients having received varying doses of concurrent steroids, evidence to support the use of HBO in radionecrosis remains weak [44].

The utilization of heat in cancer therapy is not a new concept, with radiofrequency, microwaves and ultrasound all being used to treat brain tumors [49-51]. The difficulty has remained controlling the distribution of hyperthermia within the target tissue, thus avoiding damage to normal brain parenchyma. This makes interstitial thermotherapy an ideal choice because of improved localization and dispersal within target tissue [52]. Interstitial thermotherapy is minimally invasive and mainly used to treat deep-seated, primarily inoperable brain tumors [53]. Various clinical studies conducted using different devices have all shown responses ranging from remission to shrinking tumor sizes as well as prolonged survival as assessed by clinical and imaging follow-up $[54,55]$. The limitations with the initial probes using Nd:YAG lasers were because of their inability to control penetration depths, susceptibility to char, and uncertainty of extent of coagulation resulting in risk to adjacent normal tissues [56]. Using real-time MR imaging and thermometry during the procedure, accurate temperature measurements within the targeted lesion as well as adjacent cerebral structures can be accurately calculated, thus limiting any unnecessary thermal damage to nonlesional cortex.

Intraoperative detection of the perinecrotic or gliotic zone in $\mathrm{RN}$ has been performed and reported using fluorescence of protoporphyrin IX [57], with surgical resection of this zone demonstrating rapid improvements both radiologically and clinically [28]. Our hypothesis in using LITT to treat cerebral RN was to replace the endothelial proliferating cells and zone of disorganized angiogenesis with thrombosed vessels. The perinecrotic zone (gliotic) zone was also targeted in the treatment volume, and real-

Stereotact Funct Neurosurg 2012;90:192-200 
time thermal isodose contours confirmed complete ablative treatment of the predefined target region (which included the necrotic center, contrast-enhancing periphery and the perinecrotic/gliotic zone for which we included a margin of about $0.5 \mathrm{~cm}$ all around the target lesion). Functionally, the perinecrotic zone is responsible for much of the VEGF release, which is a potent angiogenic peptide and cause of vasogenic edema, causing further release of HIF- $1 \alpha$ and ICAM- 1 activation as well. By targeting this gliotic zone with LITT, the dysfunctional astrocytes and endothelial cells undergo coagulative necrosis effectively removing most of the source of active VEGF.

In this case, there were several clinical factors that led us to use LITT: (1) prolonged steroid therapy had not resulted in clinical improvement and destabilized the patient's diabetes, (2) the lesion was located in the centrum semiovale and was deep-seated which we felt could not be safely resected via open cranial surgery without causing neurological deficits, (3) the patient's comorbidities and antiplatelet therapy prevented the use of BEV, and (4) the progressively worsening symptoms warranted urgent intervention. We used the AutoLITT ${ }^{\circledR}$ device because of the advantages this treatment system has for laser thermal ablation of lesions; namely (a) the laser fires from within the tumor, (b) the surgeon has control over the direction, depth, and duration of fire, (c) thermal damage ceases virtually immediately when the laser is shut off, limiting tissue death to the tumor and avoiding unwanted damage to nearby healthy tissue and structures, and (d) thermal damage threshold lines accurately predict the extent of tissue coagulation. The first-in-man trials using the $\mathrm{Au}-$ toLITT $^{\circledR}$ device (Monteris medical) in the setting of recurrent glioblastoma were completed in 2009 with results revealing a significantly improved median survival in the treated group [manuscript in preparation].

Various studies have reported early and late MRI findings in patients undergoing LITT for brain tumors [58]. Acute lesions consisted of reverse signal intensities on $\mathrm{T}_{1^{-}}$and $\mathrm{T}_{2}$-weighted imaging, with a high signal in the center of the lesion, and low signal intensities in the periphery on $\mathrm{T}_{1}$ sequences. Late (mean 93 days) imaging revealed a reduction in lesion size with an enhancing rim that persisted for a long duration. In this case, the patient had early symptomatic improvement, was able to be completely weaned off of steroids, and had marked reduction of edema, which provides evidence that the treatment was effective. Although 7-week postoperative imaging showed an increase in lesion size, it is possible that this is consistent with the natural course after LITT therapy as seen in tumors treated with LITT [58].
There are several limitations to this study. First, it is a single case that demonstrates that it is feasible to treat RN with LITT and is suggestive of a treatment effect. A prospective study with a larger number of patients with medically refractory $\mathrm{RN}$ would need to be performed to further evaluate the efficacy of LITT to treat RN. Second, stereotactic tissue biopsy is required to obtain a diagnosis. Given that the diagnostic yield ranges between 80 $96 \%$, the possibility of a mixed lesion cannot be discounted $[59,60]$. We did use PET-CT which has a sensitivity of $86 \%$ and specificity of $80 \%$ as an initial investigation for diagnosing $\mathrm{RN}$ in this case [61]. In addition, biopsies from the gliotic zone with immunostaining before and after the procedure may increase diagnostic yield; however, the risk of multiple entries and biopsy sites may not be justified.

\section{Conclusion}

LITT is a safe technique for treating focal cerebral radionecrosis, with good control of cerebral edema along with clinical improvement evident on short (7-week) follow-up. LITT may be an effective option for medically refractory radionecrosis that is not amenable to surgical decompression. Its effect in radiation-induced injury needs to be studied further.

\section{Acknowledgements}

The authors wish to thank Ms. Christine Moore and Ms. Martha Tobin for their assistance with the preparation of the manuscript.

\footnotetext{
References $>1$ Feigl GC, Horstmann GA: Volumetric follow up of brain metastases: a useful method to evaluate treatment outcome and predict survival after Gamma Knife surgery? J Neurosurg 2006;105 suppl:91-98.

-2 Giglio P, Gilbert MR: Cerebral radiation necrosis. Neurologist 2003;9:180-188.

-3 McPherson CM, Warnick RE: Results of contemporary surgical management of radiation necrosis using frameless stereotaxis and intraoperative magnetic resonance imaging. J Neurooncol 2004;68:41-47.

-4 Torcuator R, Zuniga R, Mohan YS, Rock J, Doyle T, Anderson J, et al: Initial experience with bevacizumab treatment for biopsy confirmed cerebral radiation necrosis. J Neurooncol 2009;94:63-68.
}

Rahmathulla/Recinos/Valerio/Chao/ Barnett 
5 Kohshi K, Imada H, Nomoto S, Yamaguchi $\mathrm{R}$, Abe H, Yamamoto H: Successful treatment of radiation-induced brain necrosis by hyperbaric oxygen therapy. J Neurol Sci 2003;209:115-117.

-6 Maroon JC, Onik G, Quigley MR, Bailes JE, Wilberger JE, Kennerdell JS: Cryosurgery revisited for the removal and destruction of brain, spinal and orbital tumours. Neurol Res 1992;14:294-302.

7 Ram Z, Cohen ZR, Harnof S, Tal S, Faibel M, Nass D, et al: Magnetic resonance imagingguided, high-intensity focused ultrasound for brain tumor therapy. Neurosurgery 2006; 59:949-955; discussion 955-956.

$\checkmark 8$ Anzai Y, Lufkin R, DeSalles A, Hamilton DR, Farahani K, Black KL: Preliminary experience with MR-guided thermal ablation of brain tumors. AJNR Am J Neuroradiol 1995; 16:39-48; discussion 49-52.

-9 Roux FX, Merienne L, Fallet-Bianco C, Beuvon F, Devaux B, Leriche B, et al: [Stereotaxic laser interstitial thermotherapy. A new alternative in the therapeutic management of some brain tumors]. Neurochirurgie 1992; 38:238-244.

10 Laidler KJ: The development of the Arrhe nius equation. J Chem Educ 1984;61:494.

- 11 Kahn T, Harth T, Kiwit JC, Schwarzmaier HJ, Wald C, Modder U: In vivo MRI thermometry using a phase-sensitive sequence: preliminary experience during MRI-guided laser-induced interstitial thermotherapy of brain tumors. J Magn Reson Imaging 1998; 8:160-164.

12 Bown SG: Phototherapy in tumors. World J Surg 1983;7:700-709.

13 Sugiyama K, Sakai T, Fujishima I, Ryu H, Uemura K, Yokoyama T: Stereotactic interstitial laser-hyperthermia using Nd-YAG laser. Stereotact Funct Neurosurg 1990;54-55 501-505.

14 Ascher PW, Justich E, Schrottner O: A new surgical but less invasive treatment of central brain tumours Preliminary report. Acta Neurochir Suppl (Wien) 1991;52:78-80.

-15 Kahn T, Bettag M, Ulrich F, Schwarzmaier HJ, Schober R, Furst G, et al: MRI-guided laser-induced interstitial thermotherapy of cerebral neoplasms. J Comput Assist Tomogr 1994;18:519-532.

- 16 Carpentier A, McNichols RJ, Stafford RJ, Guichard JP, Reizine D, Delaloge S, et al: Laser thermal therapy: real-time MRI-guided and computer-controlled procedures for metastatic brain tumors. Lasers Surg Med 2011;43:943-950.

- 17 Carpentier A, McNichols RJ, Stafford RJ, Itzcovitz J, Guichard JP, Reizine D, et al: Real-time magnetic resonance-guided laser thermal therapy for focal metastatic brain tumors. Neurosurgery 2008;63:ONS21-28; discussion ONS28-29.
18 Frazier JL, Batra S, Kapor S, Vellimana A, Gandhi R, Carson KA, et al: Stereotactic radiosurgery in the management of brain metastases: an institutional retrospective analysis of survival. Int J Radiat Oncol Biol Phys 2010;76:1486-1492.

19 Williams BJ, Suki D, Fox BD, Pelloski CE, Maldaun MV, Sawaya RE, et al: Stereotactic radiosurgery for metastatic brain tumors: a comprehensive review of complications. J Neurosurg 2009;111:439-448.

20 Kumar AJ, Leeds NE, Fuller GN, Van Tassel P, Maor MH, Sawaya RE, et al: Malignant gliomas: MR imaging spectrum of radiation therapy- and chemotherapy-induced necrosis of the brain after treatment. Radiology 2000;217:377-384.

21 Minniti G, Clarke E, Lanzetta G, Osti MF, Trasimeni G, Bozzao A, et al: Stereotactic radiosurgery for brain metastases: analysis of outcome and risk of brain radionecrosis. Radiat Oncol 2011;6:48.

22 Soussain C, Ricard D, Fike JR, Mazeron JJ, Psimaras D, Delattre JY: CNS complications of radiotherapy and chemotherapy. Lancet 2009;374:1639-1651.

23 Brown WR, Thore CR, Moody DM, Robbins ME, Wheeler KT: Vascular damage after fractionated whole-brain irradiation in rats. Radiat Res 2005;164:662-668.

24 Pena LA, Fuks Z, Kolesnick RN: Radiationinduced apoptosis of endothelial cells in the murine central nervous system: protection by fibroblast growth factor and sphingomyelinase deficiency. Cancer Res 2000;60:321327.

-25 Keck PJ, Hauser SD, Krivi G, Sanzo K, Warren T, Feder J, et al: Vascular permeability factor, an endothelial cell mitogen related to PDGF. Science 1989;246:1309-1312.

26 Leung DW, Cachianes G, Kuang WJ, Goeddel DV, Ferrara N: Vascular endothelial growth factor is a secreted angiogenic mitogen. Science 1989;246:1306-1309.

27 Nordal RA, Nagy A, Pintilie M, Wong CS: Hypoxia and hypoxia-inducible factor-1 target genes in central nervous system radiation injury: a role for vascular endothelial growth factor. Clin Cancer Res 2004;10:3342-3353.

28 Nonoguchi N, Miyatake S, Fukumoto M, Furuse M, Hiramatsu R, Kawabata S, et al: The distribution of vascular endothelial growth factor-producing cells in clinical radiation necrosis of the brain: pathological consideration of their potential roles. J Neurooncol 2011;105:423-431.

29 Burger PC, Boyko OB: The pathology of central nervous system radiation injury; in $\mathrm{Gu}$ tin PH, Leibel SA, Sheline GE (eds): Radiation Injury to the Nervous System. New York, Raven, 1991, pp 191-208.

30 Burger PC, Mahaley Jr MS, Dudka L, Vogel FS: The morphologic effects of radiation administered therapeutically for intracranial gliomas. A postmortem study of 25 cases. Cancer 1979;44:1256-1272.
31 Daigle JL, Hong JH, Chiang CS, McBride WH: The role of tumor necrosis factor signaling pathways in the response of murine brain to irradiation. Cancer Res 2001;61: 8859-8865.

32 Gonzalez J, Kumar AJ, Conrad CA, Levin VA: Effect of bevacizumab on radiation necrosis of the brain. Int J Radiat Oncol Biol Phys 2007;67:323-326.

33 Rizzoli HV, Pagnanelli DM: Treatment of delayed radiation necrosis of the brain. A clinical observation. J Neurosurg 1984;60: 589-594.

34 Glantz MJ, Burger PC, Friedman AH, Radtke RA, Massey EW, Schold SC Jr: Treatment of radiation-induced nervous system injury with heparin and warfarin. Neurology 1994; 44:2020-2027.

35 Happold C, Ernemann U, Roth P, Wick W, Weller M, Schmidt F: Anticoagulation for radiation-induced neurotoxicity revisited. J Neurooncol 2008;90:357-362.

36 Dion MW, Hussey DH, Doornbos JF, Vigliotti AP, Wen BC, Anderson B: Preliminary results of a pilot study of pentoxifylline in the treatment of late radiation soft tissue necrosis. Int J Radiat Oncol Biol Phys 1990; 19:401-407.

-37 Delanian S, Porcher R, Balla-Mekias S, Lefaix JL: Randomized, placebo-controlled trial of combined pentoxifylline and tocopherol for regression of superficial radiationinduced fibrosis. J Clin Oncol 2003;21: 2545-2550.

38 Lefaix JL, Delanian S, Vozenin MC, LeplatJJ, Tricaud Y, Martin M: Striking regression of subcutaneous fibrosis induced by high doses of gamma rays using a combination of pentoxifylline and alpha-tocopherol: an experimental study. Int J Radiat Oncol Biol Phys 1999;43:839-847.

39 Okunieff P, Augustine E, Hicks JE, Cornelison TL, Altemus RM, Naydich BG, et al: Pentoxifylline in the treatment of radiationinduced fibrosis. J Clin Oncol 2004;22:22072213.

40 Ozturk B, Egehan I, Atavci S, Kitapci M: Pentoxifylline in prevention of radiation-induced lung toxicity in patients with breast and lung cancer: a double-blind randomized trial. Int J Radiat Oncol Biol Phys 2004;58: 213-219.

41 Williamson R, Kondziolka D, Kanaan H, Lunsford LD, Flickinger JC: Adverse radiation effects after radiosurgery may benefit from oral vitamin $\mathrm{E}$ and pentoxifylline therapy: a pilot study. Stereotact Funct Neurosurg 2008;86:359-366.

42 New P: Radiation injury to the nervous system. Curr Opin Neurol 2001;14:725-734.

43 Feldmeier JJ: Hyperbaric oxygen for delayed radiation injuries. Undersea Hyperb Med 2004;31:133-145. 
-44 Pasquier D, Hoelscher T, Schmutz J, Dische $S$, Mathieu D, Baumann M, et al: Hyperbaric oxygen therapy in the treatment of radio-induced lesions in normal tissues: a literature review. Radiother Oncol 2004;72:1-13.

45 Hart GB, Mainous EG: The treatment of radiation necrosis with hyperbaric oxygen (OHP). Cancer 1976;37:2580-2585.

46 Chuba PJ, Aronin P, Bhambhani K, Eichenhorn M, Zamarano L, Cianci P, et al: Hyperbaric oxygen therapy for radiation-induced brain injury in children. Cancer 1997;80: 2005-2012.

-47 Leber KA, Eder HG, Kovac H, Anegg U, Pendl G: Treatment of cerebral radionecrosis by hyperbaric oxygen therapy. Stereotact Funct Neurosurg 1998;70 Suppl 1:229-236.

-48 Takenaka N, Imanishi T, Sasaki H, Shimazaki K, Sugiura H, Kitagawa Y, et al: Delayed radiation necrosis with extensive brain edema after gamma knife radiosurgery for multiple cerebral cavernous malformations case report. Neurol Med Chir (Tokyo) 2003; 43:391-395.

49 Britt RH, Pounds DW, Lyons BE: Feasibility of treating malignant brain tumors with focused ultrasound. Prog Exp Tumor Res 1984; 28:232-245.
50 Roberts DW, Coughlin CT, Wong TZ, Fratkin JD, Douple EB, Strohbehn JW: Interstitial hyperthermia and iridium brachytherapy in treatment of malignant glioma. A phase I clinical trial. J Neurosurg 1986;64:581-587.

51 Winter A, Laing J, Paglione R, Sterzer F: Microwave hyperthermia for brain tumors. Neurosurgery 1985;17:387-399.

52 Strohbehn JW, Douple EB: Hyperthermia and cancer therapy: a review of biomedical engineering contributions and challenges. IEEE Trans Biomed Eng 1984;31:779-787.

53 Menovsky T, Beek JF, Roux FX, Bown SG: Interstitial laser thermotherapy: developments in the treatment of small deep-seated brain tumors. Surg Neurol 1996;46:568-571; discussion 571-562.

54 Ascher PW, Justich E, Schrottner O: Interstitial thermotherapy of central brain tumors with the Nd:YAG laser under real-time monitoring by MRI. J Clin Laser Med Surg 1991; 9:79-83.

55 Kahn T, Bettag M, Harth T, Schwabe B, Schwarzmaier HJ, Modder U: [Laser-induced interstitial induced hyperthermia of cerebral tumors with nuclear magnetic resonance tomography control]. Radiologe 1996; 36:713-721.
56 Svaasand LO, Ellingsen R: Optical penetration in human intracranial tumors. Photochem Photobiol 1985;41:73-76.

57 Miyatake S, Kuroiwa T, Kajimoto Y, Miyashita M, Tanaka H, Tsuji M: Fluorescence of non-neoplastic, magnetic resonance imaging-enhancing tissue by 5 -aminolevulinic acid: case report. Neurosurgery 2007;61: E1101-E1103; discussion E1103-E1104.

58 Schwabe B, Kahn T, Harth T, Ulrich F, Schwarzmaier HJ: Laser-induced thermal lesions in the human brain: short- and longterm appearance on MRI. J Comput Assist Tomogr 1997;21:818-825.

59 Hall WA: The safety and efficacy of stereotactic biopsy for intracranial lesions. Cancer 1998;82:1749-1755.

60 Hall WA, Liu H, Martin AJ, Truwit CL: Comparison of stereotactic brain biopsy to interventional magnetic-resonance-imagingguided brain biopsy. Stereotact Funct Neurosurg 1999;73:148-153.

61 Chao ST, Suh JH, Raja S, Lee SY, Barnett G: The sensitivity and specificity of FDG PET in distinguishing recurrent brain tumor from radionecrosis in patients treated with stereotactic radiosurgery. Int J Cancer 2001;96: 191-197. 